\title{
DETERMINAÇÃO DE PESTICIDAS ORGANOCLORADOS EM ÁGUA DE MANANCIAL, ÁGUA POTÁVEL E SOLO NA REGIÃO DE BAURU (SP)
}

Sandra Regina Rissato*

Departamento de Química,Universidade Estadual Paulista, CP 473, 17033-360 Bauru - SP

Marcelo Libânio

Departamento de Engenharia Hidráulica e Recursos Hídricos, Universidade Federal de Minas Gerais, 30110-060 Belo Horizonte - MG

Giselda Passos Giafferis

Divisão de Produção e Reservação, Departamento de Água e Esgoto, Bauru - SP

Marli Gerenutti

Farmácia e Bioquímica, Centro de Ciências Biológicas e da Saúde, Universidade de Sorocaba, Sorocaba - SP

Recebido em 6/10/03; aceito em 2/3/04; publicado na web em 17/6/04

\begin{abstract}
DETERMINATION OF ORGANOCHLORATED PESTICIDES IN THE WATER SUPPLY SYSTEM, DRINKING WATER AND SOIL OF THE REGION OF BAURU (SP). This paper evaluates the presence of organochlorinated pesticides in the water supply system of the city of Bauru, State of São Paulo, Brazil. Soil samples were collected in agricultural areas and water samples at several points of the water source (river) and the distribution net. The results of the analyses of the water from the source were compared with the Brazilian classification system for inland waters (CONAMA/86) and the results of analyses of treated water were compared with Brazilian standards for finished drinking water.
\end{abstract}

Keywords: organochlorinated pesticides; water; soil; gas chromatograph.

\section{INTRODUÇÃO}

O grande emprego de pesticidas orgânicos na agricultura desde 1940 promoveu, além de colheitas com qualidade, um aumento na produtividade possibilitando o atendimento da demanda alimentícia na maioria dos países ${ }^{1}$.

Apesar dos benefícios que trazem os pesticidas, o problema de intoxicações por defensivos agrícolas preocupa as autoridades, especialmente pelo fato de que essas intoxicações acontecem pela ingestão gradativa destes produtos que contaminam a água, o solo e uma variedade de alimentos ${ }^{2}$. O uso de muitos destes compostos foi proibido devido à constatação do efeito cumulativo e prejudicial, que ocorre pela transferência de pequenas quantidades ao longo das cadeias alimentares ${ }^{3}$

O emprego de pesticidas organoclorados, nas últimas décadas, tem produzido acumulação de resíduos tóxicos em vários ecossistemas em todo mundo. A concentração destes compostos tem alcançado níveis tóxicos em vários organismos terrestres, como pássaros e mamíferos, assim como em organismos aquáticos. Os resíduos de pesticidas organoclorados têm se tornado parte intrínseca dos ciclos biológicos, geológicos e químicos da Terra e têm sido detectados no ar, água, solo, plantas, invertebrados marinhos e mesmo, na neve e em pingüins da Antártica e do Ártico onde eles não são emprega$\operatorname{dos}^{4,5}$.

Os pesticidas organoclorados são relativamente inertes e sua alta estabilidade está relacionada às ligações carbono-cloro. Estes compostos são muito estudados devido à alta toxicidade, baixa biodegradabilidade e biossolubilidade em tecido lipídico ${ }^{6-8}$. Alguns destes compostos podem persistir por 15 a 20 anos no solo e parte destes serem arrastados pelas chuvas (por lixiviação) para o interior dos cursos de água, que também recebem estes compostos através de efluentes industriais, de esgotos, de sedimentos, da atmosfera e por

*e-mail: srissato@fc.unesp.br contaminação direta durante a aplicação. Assim, tanto as águas de mananciais de rios e represas que abastecem as populações, quanto os peixes que se alimentam de materiais retirados do fundo desses locais apresentam concentração de agrotóxicos, mesmo anos após a cessar a aplicação destes em regiões vizinhas ${ }^{1}$. A avaliação de efeitos cumulativos de pesticidas em ecossistemas aquáticos tem sido realizada através de testes de laboratório, utilizando testes agudos $\left(\mathrm{LC}_{50}\right)$ e crônicos $(\mathrm{BCF})^{6,9}$. Pesquisas demonstraram que o fator de bioconcentração (BCF) para compostos lipofílicos, como os organoclorados, apresentam valores mais elevados em organismos que ocupam níveis tróficos maiores ${ }^{10}$.

Apesar de parte destes micropoluentes se acumularem ao longo da cadeia alimentar, grande parte ainda permanece nos corpos da água podendo contaminaá-la, tornando-a imprópria para consumo ${ }^{11}$.

Pesticidas organoclorados em água potável podem aumentar os riscos de ocorrência de câncer, bem como causar danos aos sistemas nervoso, cardíaco, endócrino e reprodutivo ${ }^{2}$. Como as águas superficiais são fontes vitais de água potável, a qualidade da água tem recebido considerável atenção nas legislações ambientais. Por exemplo, a União Européia (EU) preconiza que a concentração de pesticidas individuais em água potável não deve exceder $0,1 \mu \mathrm{g} / \mathrm{L}^{12}$. Os níveis máximos de contaminantes ("Maximum Contaminant Level, MCL") têm sido estabelecidos pelo "Environmental Protection Agency (EPA)" para muitos pesticidas, incluindo os organoclorados ${ }^{13}$.

Os tratamentos de água convencionais são inefetivos na remoção de pesticidas organoclorados ${ }^{14-16} \mathrm{e}$, em muitos casos, a concentração desses pesticidas na água de consumo é similar à dos mananciais ${ }^{13}$.

Os sistemas de tratamento alternativo de águas, tais como filtração (usando carbono ativado granular), poderiam ser utilizados para melhorar a qualidade da água potável, entretanto, além de custo elevado, muitas vezes não atingem os padrões satisfatórios de qualida$\mathrm{de}^{13}$.

Além disso, os pesticidas organoclorados podem ser adsorvidos por partículas de argila, as quais geram turbidez em águas naturais, 
sendo que ultimamente estes compostos têm sido removidos por sedimentação e filtração ${ }^{17,18}$.

Diante deste panorama, há necessidade de monitoramento constante dos níveis de concentração em receptáculos como solos e águas. $\mathrm{O}$ atendimento desta necessidade tem motivado o desenvolvimento de diferentes métodos analíticos visando a identificação e quantificação de resíduos de pesticidas ${ }^{19}$.

Este trabalho apresenta uma metodologia para avaliação do risco potencial de resíduos de pesticidas organoclorados em águas de mananciais, água potável e solo, tendo sido aplicada na região de Bauru-SP. Para a determinação dos pesticidas BHC, Dieldrin, Endosulfan Alfa, Endosulfan Beta, Endosulfan Sulfato, Aldrin, Heptaclor e DDT, estes foram extraídos e quantificados de acordo com métodos descritos na literatura ${ }^{20,21}$. As amostras de água e solo foram coletadas durante período de nove meses e submetidas a processos de extração, limpeza e análise por cromatografia a gás utilizando um detector de captura de elétrons (HRGC/ECD).

\section{PARTE EXPERIMENTAL}

\section{Reagentes}

Todos os solventes utilizados foram Mallinkrodt (Merck) grau pesticida. A água deionizada foi de grau Milli- ${ }^{\circledR}$ (Millipore, Bedford, MA, USA), produzida a $18,5 \mathrm{M} \Omega \mathrm{cm}^{-1}$.

As soluções estoque foram preparadas a partir dos padrões de referência certificados (pureza $\geq 98 \%$, todos Chem Service Inc.) dissolvidos em metanol, na concentração de $1 \mathrm{mg} / \mathrm{L}$ e as soluções de trabalho foram obtidas a partir da diluição da solução estoque para as amostras fortificadas.

Para a extração em fase sólida (SPE) foram utilizados cartuchos Octadecyl (C-18) 500 mg (J. T. Baker), na concentração dos pesticidas estudados.

\section{Amostras}

O estudo de monitoramento foi iniciado na primavera de 2002 e as amostras foram coletadas em três períodos:

Período 1: Outubro / Novembro / Dezembro

Período 2: Janeiro / Fevereiro / Março

Período 3: Abril / Maio / Junho

As áreas para amostragem de água dos rios Batalha e Bauru que abastecem a cidade de Bauru, como também para o solo, foram selecionadas em regiões agrícolas, próximas às plantações de maior produção da região, isto é, de cana de açúcar.

Todas as amostragens foram realizadas em locais de acordo com os mapas de estradas e topográficos, sempre levando em consideração a situação geológica típica da região de Bauru.

As amostras de água potável (ou tratada) foram coletadas em áreas próximas da Estação de Tratamento de Água de Bauru (cerca de 1 km).

Todas as amostras foram coletadas em quintuplicata, para avaliação da precisão pelo cálculo do desvio padrão relativo (DPR) do método.

\section{Coleta das amostras}

\section{Águas de mananciais}

As amostras dos rios Batalha e Bauru foram coletadas duas vezes por semana, em média. Todas as amostras foram filtradas em filtro de fibra de vidro de $1 \mu \mathrm{m}$ para remoção de material particulado e colóides, utilizando-se uma bomba peristáltica.

Em cada ponto, as amostras foram coletadas conectando-se um recipiente de vidro âmbar de $1 \mathrm{~L}$ a uma camisa de metal com haste usada para auxiliar no mergulho e preenchimento do recipiente. Esse recipiente continha um orifício de entrada calibrado a uma velocidade de mergulho controlada, garantindo linearidade de fluxo e volume durante a coleta, para a profundidade estudada (cerca de $1 \mathrm{~m}$ ). Após a coleta, a camisa de metal foi retirada e os frascos vedados, resfriados com gelo em isopor, para transporte até o laboratório. Os frascos contendo as amostras foram devidamente resfriados a $4{ }^{\circ} \mathrm{C}$, onde permaneceram até o momento da extração.

Para cada período, foi designado um "local de fortificação" para amostragens, onde quatro amostras extras foram coletadas, resfriadas e acondicionadas, de acordo com os procedimentos acima descritos. Estas amostras foram fortificadas pipetando-se diferentes alíquotas da solução de trabalho contendo os seis pesticidas estudados na concentração de $1 \mathrm{mg} / \mathrm{L}$. Alíquotas de 0,1, 0,5 e 1,0 mL foram adicionadas a $1 \mathrm{~L}$ de amostras de água para as concentrações finais de $0,1,0,5$ e $1,0 \mu \mathrm{g} / \mathrm{L}$, respectivamente. Amostras fortificadas e amostras testemunhas foram extraídas ao mesmo tempo em cada etapa do processo, para certificação da integridade dos dados obtidos.

\section{Água potável}

As amostras de água potável foram coletadas duas vezes por semana em média, em frascos de vidro âmbar de $1 \mathrm{~L}$. Os frascos de vidro foram vedados e resfriados temporariamente com gelo para o transporte até o laboratório, onde permaneceram a $4{ }^{\circ} \mathrm{C}$ até o momento da extração.

A fortificação foi realizada utilizando-se água purificada MilliQ pipetando-se diferentes alíquotas da solução de trabalho contendo os seis pesticidas estudados na concentração de $1 \mathrm{mg} / \mathrm{L}$. Alíquotas de $0,1,0,5$ e 1,0 mL foram adicionadas a $1 \mathrm{~L}$ de água para as concentrações finais de $0,1,0,5$ e $1,0 \mu \mathrm{g} / \mathrm{L}$, respectivamente. As amostras obtidas foram, em seguida, submetidas aos processos de extração.

Solo

As amostras de solo foram coletadas duas vezes por semana, em média. A coleta foi realizada em solos de plantações de cana de açúcar em regiões próximas aos rios Batalha e Bauru, através da escavação de um orifício de $30 \times 10 \mathrm{~cm}$, com o auxílio de um trado e estocadas em freezer a $-18^{\circ} \mathrm{C}$ até o momento da extração.

As amostras foram secas a $30 \pm 5^{\circ} \mathrm{C}$. Fragmentos e pedras visíveis foram retirados e, em seguida, as amostras foram trituradas mecanicamente, peneiradas em peneira de 60 mesh para garantir a homogeneidade da amostra e facilitar o processo de extração.

Amostras testemunhas foram obtidas pela extração de $50 \mathrm{~g}$ de solo devidamente triturado e peneirado com $250 \mathrm{~mL}$ of acetonitrila por $18 \mathrm{~h}$, seguido pela extração com $150 \mathrm{~mL}$ de $\mathrm{n}$-hexano/acetona $(1: 1, \mathrm{v} / \mathrm{v})$ por $8 \mathrm{~h}$. A amostra de solo obtida foi seca a $50{ }^{\circ} \mathrm{C}$ e mantida em dessecador até o momento da extração. As análises cromatográficas obtidas mostraram que as amostras testemunhas estavam livres de resíduos de pesticidas organoclorados ou qualquer outro interferente.

As amostras testemunhas de solo (cerca de $10 \mathrm{~g}$ ) foram então fortificadas pipetando-se diferentes alíquotas da solução de trabalho contendo os seis pesticidas estudados na concentração de $0,01 \mathrm{mg} / \mathrm{L}$. Alíquotas de 0,1,0,5 e 1,0 mL foram adicionadas a $10 \mathrm{~g}$ de solo para as concentrações finais de $0,1,0,5$ e $1,0 \mu \mathrm{g} / \mathrm{L}$, respectivamente. $\mathrm{O}$ solvente foi evaporado até a secura sob fluxo de nitrogênio à temperatura ambiente e as amostras, submetidas ao processo de extração.

\section{Extração}

\section{Amostras de água}

A concentração e a purificação das amostras de água foram realizadas por Extração em Fase Sólida (SPE), com cartuchos SPE-C-18 
Tabela 1. Recuperações e desvios padrão relativos (DPR \%) das extrações de cada pesticida em água deionizada e águas de mananciais fortificadas (em 3 diferentes níveis de concentração)

\begin{tabular}{lcccccc}
\hline & \multicolumn{5}{c}{ Recuperação (DPR \%)* } \\
\cline { 2 - 7 } Pesticidas & $0,1 \mu \mathrm{g} / \mathrm{L}$ & $0,5 \mu \mathrm{g} / \mathrm{L}$ & $1,0 \mu \mathrm{g} / \mathrm{L}$ & $0,1 \mu \mathrm{g} / \mathrm{L}$ & $0,5 \mu \mathrm{g} / \mathrm{L}$ & $1,0 \mu \mathrm{g} / \mathrm{L}$ \\
\cline { 2 - 7 } & $94,5(4,5)$ & $95,6(3,9)$ & $97,3(3,8)$ & $81,5(5,3)$ & $83,2(4,6)$ & $86,7(3,9)$ \\
\hline BHC & $92,7(4,3)$ & $96,1(4,1)$ & $98,5(3,6)$ & $81,2(4,3)$ & $82,4(4,9)$ & $85,0(4,2)$ \\
Dieldrin & $93,8(5,5)$ & $95,3(3,8)$ & $98,8(4,1)$ & $82,6(4,2)$ & $81,2(4,1)$ & $86,8(3,5)$ \\
Endosulfan & $94,7(5,1)$ & $96,8(3,5)$ & $97,9(3,3)$ & $80,9(4,9)$ & $84,8(4,9)$ & $87,8(3,7)$ \\
Aldrin & $95,8(4,6)$ & $97,1(4,2)$ & $98,2(3,9)$ & $82,3(4,5)$ & $82,9(5,4)$ & $87,6(4,1)$ \\
Heptachlor & $97,3(4,2)$ & $96,5(3,9)$ & $97,9(3,7)$ & $81,8(3,9)$ & $83,4(5,1)$ & $85,5(3,8)$ \\
DDT & &
\end{tabular}

*Desvio Padrão Relativo (DPR\%) baseado em quintuplicata.

como adsorvente e sistema à vácuo Supelco Visiprep. Cinco amostras de água foram extraídas pelo seguinte procedimento:

1 - Condicionamento do cartucho com 2 x $5 \mathrm{~mL}$ de metanol a um fluxo de $10 \mathrm{~mL} / \mathrm{min}$.

2 - Condicionamento do cartucho com $10 \mathrm{~mL}$ de água deionizada a um fluxo de $10 \mathrm{~mL} / \mathrm{min}$.

3 - Inserção de $1000 \mathrm{~mL}$ de amostra de água no cartucho SPE, mantendo-se o fluxo a $10 \mathrm{~mL} / \mathrm{min}$.

4 - Lavagem do cartucho com $10 \mathrm{~mL}$ de água deionizada.

5 - Secagem do cartucho sob vácuo, por $20 \mathrm{~min}$, para eliminar os traços de água.

6 - Eluição do cartucho com $5 \mathrm{~mL}$ de acetato de etila (sob vácuo).

7 - Eluição do cartucho com $5 \mathrm{~mL}$ de diclorometano (sob vácuo).

As alíquotas finais foram combinadas (10 mL de eluentes), concentradas por fluxo de $\mathrm{N}_{2}$ à secura e seu volume ajustado com $1 \mathrm{~mL}$ de n-hexano sendo, em seguida, submetidas à análise por HRGC/ ECD.

Os procedimentos de preparação e extração intensificaram em 100 vezes a concentração do analito.

\section{Amostras de solo}

$10 \mathrm{~g}$ de amostra de solo (após secagem, trituração e peneiramento) foram extraídos com $100 \mathrm{~mL}$ de n-hexano, com agitação constante por $30 \mathrm{~min}$. Em seguida, a suspensão foi centrifugada por $20 \mathrm{~min}$ e a camada líquida filtrada em filtro de membrana de vidro $(0,22 \mu \mathrm{m})$, sendo que as operações de agitação e filtração foram repetidas.

Os extratos combinados foram concentrados à secura em rotaevaporador sob vácuo a temperatura de $45^{\circ} \mathrm{C}$. O resíduo foi solubilizado em $1 \mathrm{~mL}$ de n-hexano para análise por HRGC/ECD. Os processos de fortificação foram realizados em quintuplicata para cada nível, em conjunto com uma testemunha, sendo extraídos e analisados para avaliação da precisão (desvio padrão relativo), como também para controle de possíveis interferentes provenientes do processo analítico.

\section{Análise}

Os extratos obtidos foram então submetidos à análise por HRGC em cromatógrafo a gás HP 5890 Series II equipado com detector de captura de elétrons $\left(\mathrm{ECD}-{ }^{63} \mathrm{Ni}\right)$ a $300{ }^{\circ} \mathrm{C}$, usando $\mathrm{H}_{2}$ como gás de arraste $(\bar{\mu}=38 \mathrm{~cm} / \mathrm{s})$ e fluxo de "make-up" $\mathrm{N}_{2} 66 \mathrm{~mL} / \mathrm{min}$. A coluna utilizada foi uma LM-5 (5\% fenildimetilpolisiloxano) de $30 \mathrm{~m} \mathrm{x}$ $0,25 \mathrm{~mm}$ com filme na espessura de $0,35 \mu \mathrm{m}$. A temperatura do forno foi de $80{ }^{\circ} \mathrm{C}(12 \mathrm{~min})$ até $300{ }^{\circ} \mathrm{C}(5 \mathrm{~min})$, a $8^{\circ} \mathrm{C} / \mathrm{min}$. Todas as amostras foram injetadas no modo split $(1: 15)$ a $250{ }^{\circ} \mathrm{C}$.

\section{RESULTADOS E DISCUSSÃO}

\section{Validação do método}

Os resultados de recuperação e desvio padrão relativo (eficiência de extração) para cada pesticida analisado em matrizes aquosas e em solos estão apresentados nas Tabelas 1 e 2, até o limite menor de quantificação. O limite de detecção para os pesticidas estudados foi definido como o nível no qual foi detectado, usando-se cromatografia a gás com detecção por captura de elétrons assumindo a proporção $3: 1$, sinal/ruído da linha de base.

Tabela 2. Recuperações e desvios padrão relativos (DPR \%) das extrações de cada pesticida em solo fortificado (em 3 diferentes níveis de concentração)

\begin{tabular}{lccc}
\hline Pesticidas & \multicolumn{3}{c}{ Recuperação (DPR \%)* } \\
& $0,1 \mu \mathrm{g} / \mathrm{L}$ & $0,5 \mu \mathrm{g} / \mathrm{L}$ & $1,0 \mu \mathrm{g} / \mathrm{L}$ \\
\hline BHC & $91,3(4,9)$ & $95,9(4,3)$ & $98,9(3,9)$ \\
Dieldrin & $93,4(4,5)$ & $97,3(4,1)$ & $97,9(3,8)$ \\
Endosulfan & $92,8(4,4)$ & $98,2(3,9)$ & $98,8(4,1)$ \\
Aldrin & $92,9(4,8)$ & $96,9(3,5)$ & $98,5(3,4)$ \\
Heptachlor & $94,9(5,8)$ & $98,1(3,8)$ & $98,7(3,7)$ \\
DDT & $93,5(4,9)$ & $97,9(4,1)$ & $98,6(4,0)$
\end{tabular}

*Desvio Padrão Relativo (DPR\%) baseado em quintuplicata.

Os resultados de recuperação mostraram valores que variaram de 80 a $99 \%$, com desvios padrão relativos de 3 a $6 \%(n=5)$ para os seis pesticidas estudados. Os valores de recuperação para os pesticidas em águas de rios apresentaram-se menores que aqueles obtidos a partir de água purificada; isto se deve, provavelmente, à etapa de pré-filtração. Em águas de rios as perdas desses compostos são maiores e têm sido reportadas em águas de profundidade e superficiais ${ }^{19,22}$. Este fato tem sido atribuído à competição dos sítios ativos dos adsorventes entre compostos clorados e outros grupos hidrofóbicos presentes na amostra, ou à presença de substâncias húmicas que, aparentemente, aumentam a solubilidade destes compostos ${ }^{23}$. Por outro lado, tem-se sugerido que exista uma forte tendência de pesticidas organoclorados serem adsorvidos sobre material particulado de filtros ${ }^{18,22}$. 


\section{Detecção de pesticidas organoclorados}

Os resultados de resíduos obtidos mostram maiores quantidades de BHC e Endosulfan (soma de alfa, beta e sulfato) em águas de mananciais. Além disso, os resíduos determinados em água potável (tratada) foram inferiores a $0,05 \mu \mathrm{g} / \mathrm{L}$.

A Tabela 3 apresenta a média dos resultados obtidos em todos os locais pesquisados durante os 3 períodos, de 3 meses cada. Os resultados de resíduos em água potável apresentaram a maior dispersão dos dados analíticos, especialmente no segundo período, o qual representa o início da estação de chuvas na região onde se realizaram as amostragens. $\mathrm{O}$ mesmo estudo deverá ser desenvolvido durante o mesmo período nos próximos 2 anos, visando-se a obtenção de resultados significativos, buscando-se melhor compreensão do sistema de tratamento de água da região estudada de Bauru (SP).

A presença de pesticidas em águas de mananciais poderia estar relacionada às características do solo de Bauru, pois as partículas sólidas de material mineral orgânico (argila, areia e matéria orgânica) são importantes no processo de adsorção dos pesticidas no solo, sendo que o solo mais argiloso possui maior grau de adsorção, cujo efeito é menor na região de Bauru, por apresentar um solo com tendência quartzozo (Figura 1).

Os resultados obtidos mostraram a evidência de boa eficiência do sistema de tratamento de água, com a diminuição de concentração dos pesticidas monitorados. Provavelmente, o fator mais importante na remoção dos pesticidas seja o processo de adsorção devido à presença de sólidos suspensos. A turbidez de águas naturais, especialmente no caso de rios, pode ser considerada como um fator posi- tivo para a remoção de pesticidas pois, no caso das águas de mananciais de Bauru, a turbidez contribuiu efetivamente para a redução na concentração dos pesticidas. O uso de carbono ativado é recomendado somente na situação de adsorção-sedimentação-filtração e não possui eficiência suficiente para remoção dos pesticidas aqui avaliados.

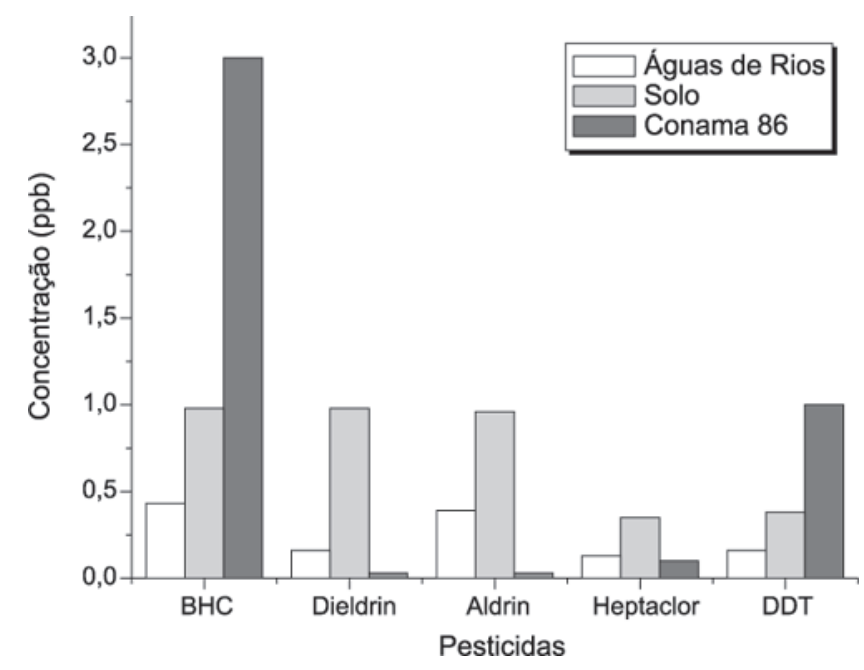

Figura 1. Resultados preliminares obtidos durante o verão de 2002 pela avaliação de amostras de águas de mananciais e solo

Tabela 3. Resultados preliminares para pesticidas organoclorados obtidos em 3 períodos, de 3 meses, em amostras de águas de mananciais, água potável e solo

\begin{tabular}{|c|c|c|c|c|c|c|c|}
\hline \multirow[t]{2}{*}{ Período } & \multirow[t]{2}{*}{ Amostras } & \multicolumn{6}{|c|}{ Resíduo (`hg/L) } \\
\hline & & $\mathrm{BHC}$ & Dieldrin & Endosulfan & Aldrin & Heptachlor & DDT \\
\hline \multirow{3}{*}{1} & Mananciais & 0,35 & 0,16 & 0,15 & 0,39 & 0,06 & 0,06 \\
\hline & Potável & 0,013 & 0,010 & 0,018 & 0,009 & 0,012 & 0,026 \\
\hline & Solo & 0,63 & 0,98 & 0,88 & 0,96 & 0,35 & 0,38 \\
\hline \multirow[t]{3}{*}{2} & Mananciais & 0,41 & 0,21 & 0,81 & 0,36 & 0,03 & 0,10 \\
\hline & Potável & 0,030 & 0,033 & 0,026 & 0,032 & 0,028 & 0,027 \\
\hline & Solo & 0,69 & 0,70 & 0,71 & 0,88 & 0,40 & 0,34 \\
\hline \multirow[t]{3}{*}{3} & Mananciais & 0,37 & 0,23 & 0,66 & 0,44 & 0,18 & 0,13 \\
\hline & Potável & 0,019 & 0,022 & 0,011 & 0,008 & 0,015 & 0,018 \\
\hline & Solo & 0,74 & 0,93 & 1,124 & 1,380 & 0,57 & 0,45 \\
\hline
\end{tabular}

\section{CONCLUSÃO}

O método utilizado para a determinação dos pesticidas organoclorados estudados apresentou eficiência com níveis de recuperação acima de $80 \%$ para as amostras de água e solo.

Os resultados obtidos para água potável estavam abaixo do limite exigido pela legislação brasileira, o que não ocorreu com as águas dos rios Batalha e Bauru (Conama/86), evidenciando boa eficiência da rede de tratamento de água da cidade de Bauru para a remoção dos pesticidas monitorados.

As pesquisas realizadas em águas de mananciais, potável e amostras de solo terão continuidade nos próximos anos, para que seja possível um estudo mais amplo sobre o tratamento de água e a remoção dos pesticidas estudados.

\section{AGRADECIMENTOS}

Ao DAE (Bauru) pelos mapas geológicos e suporte técnico, e à Fundação de Amparo a Pesquisa do Estado de São Paulo pela Bolsa Jovem Pesquisador em Centros Emergentes e pelo auxílio financeiro.

\section{REFERÊNCIAS}

1. Branco, S. M.; O Meio Ambiente em Debate, Ed. Moderna: São Paulo, 1988.

2. Rand, G. M.; Petrocelli, S. R.; Fundamentals of Aquatic Toxicology Methods and Application, Hemisphere Publishing Co: Washington, 1985.

3. Jorgenson, J.; Environ. Health Perspect. 2001, 185, 113.

4. U. S. Environmental Protection Agency (EPA); Pesticide Monitoring, Phase II Fact Sheet Series 7 (of 14): Washington, 1991. 
5. Li, Y. F.; Scholtz, M. T.; Heyst, B. J. V.; Environ. Sci. Technol. 2003, 37, 3493.

6. Galassi, S.; Vigano, L.; Sanna, M.; Chemosphere 1996, 32, 1729.

7. Kelly, A. G.; Environ. Pollut. 1995, 85, 207.

8. Lanças, F. M.; De Sá, O. R.; Galhiane, M. S.; Rissato, S. R.; Chromatographia 1996, 43, 663.

9. Lanças, F. M.; De Sá, O. R.; Galhiane, M. S.; Rissato, S. R.; J. Liq. Chromatogr. Relat. Technol. 1997, 20, 1945.

10. Stevens, J. L.; Nothcott, G. L.; Stern, G. A.; Tomy, G. T.; Jones, K. C.; Environ. Sci. Technol. 2003, 37, 462.

11. Wiles, R.; Cohen, B.; Campbell, C.; Elderkin, S.; Tap Water Blues: Herbicides in Drinking Water, Environment Working Group: Washington, 1994.

12. EEC Drinking Water Guidelines, 80/779/EEC, EEC n ${ }^{\circ}$. L229/11-29, Brussels, 1980.

13. U. S. Environmental Protection Agency (EPA); Pesticide Environmental Fate Summaries, Office of Pesticide Programs, Washington, 1992.

14. Miltner, R. J.; Baker, D. B.; Speth, T. F.; Fronk, C. A.; J. Am. Water Works Assoc. 1989, 81, 43.
15. Adams, C. D.; Randtke, S. J.; Thurman, E. M.; Hulsey, R. A. Em Proceedings from 40th Annual University of Kansas Environmental Engineering Conference; 1990.

16. Battaglin, W. A.; Hay, L. E.; Environ. Sci. Technol. 1996, 30, 889.

17. Snoeyink, V. L. Em AWWA - Water Quality and Treatment: a handbook of community water supplies; Pontius, F. W., ed.; $4^{\text {th }}$ ed., ed. McGraw-Hill, Inc.: New York, 1990.

18. Badriya, B. N.; Ravindran, V.; Den, W.; Pirbazari, M.; Water Res. 2003, 37, 4051.

19. Chagas, C. M.; Queiroz, M. E. L.; Neves, A. A.; Queiroz, J. H.; Oliveira, T. T.; Nagem, T. J.; Quim. Nova 1999, 22, 506.

20. U. S. Environmental Protection Agency (EPA); Organochlorine Pesticides and PCB, Test Method 608: Cincinnati, USA, 1984.

21. U. S. Environmental Protection Agency (EPA); Determination of Organic Compounds in Drinking Water by Liquid Solid Extraction and Capillar Column Gas Chromatography/Mass Spectrometry, Method 525: USA, 1985.

22. Barceló, D.; J. Chromatogr. 1993, 643, 117.

23. Qiang, T.; Xian-Quan, S.; Zheming, N.; Fresenius J. Anal. Chem. 1993, 347, 330. 